\title{
A imigração para o Japão ${ }^{1}$
}

\author{
ELISA SASAKI
}

\section{Introdução}

$\mathrm{N}$ AS DUAS ÚlTimas décadas do século XX, o contingente do Brasil, país até então visto como receptor de imigrantes, começou a se dirigir ao esbido um expressivo contingente de brasileiros que foram para trabalhar em ocupações de baixa qualificação, especialmente no setor manufatureiro.

Com a crise econômica no Brasil e a concomitante prosperidade no Japão, ir para o "país dos seus ancestrais" passou a ser considerado uma alternativa diante da crise econômica que marcou a situação brasileira nos anos 1980. Não são os pobres que emigram ao exterior, mas uma classe média que tem tentado manter ou elevar seu padrão de vida. Trata-se de filhos e netos de imigrantes japoneses que no início do século XX vieram ao Brasil e que estão indo agora para o Japão com as mesmas intenções de seus ancestrais: trabalhar temporariamente para retornar enriquecido para o seu país de origem. Mas a história tem nos mostrado que as intenções temporárias iniciais não têm se cumprido, por diversas razões, percorrendo trajetórias inesperadas. No caso dos imigrantes japoneses, a Segunda Guerra Mundial foi crucial para a sua fixação definitiva no solo brasileiro. Já no caso de seus descendentes no Japão, embora algumas famílias já estejam adquirindo o visto permanente e se estabelecendo no país de destino, muitos brasileiros ainda ficam divididos entre os dois países, onde transitam - entre facilidades e dificuldades - sem muita clareza em saber qual é o seu lugar.

Os brasileiros que vão para o Japão deparam com uma realidade japonesa muito diferente da imagem idealizada do país passado por seus pais e avós imigrantes no Brasil, como se tivessem congelado a cena do momento da partida, perdendo a noção do tempo durante a viagem, levando consigo as lembranças do que lhe era familiar. À medida que as novidades se esgotam nesse novo lugar, realidade, contexto e relações de diversas naturezas, os migrantes sentem saudades do que ficou, sem imaginar ou mesmo se dar conta das irrefreáveis mudanças no lugar de onde partiram - um cenário, uma sensação memorizada durante a sua ausência, guardada preciosamente no seu sentimento de pertencimento.

A partir da nova realidade vivida, os nipo-brasileiros constroem sua(s) vida(s) entre Brasil e Japão (entre a origem e destino - perdendo de vista onde é o quê), não sendo um simples somatório de elementos simbólicos e fragmentos selecionados entre Brasil e Japão de seus antepassados. Compõem uma complexa teia de conexões e de relações sociais que vão se estabelecendo em vários níveis não apenas pelos próprios migrantes e os diversos atores que participam do cenário constitutivo de redes sociais de brasileiros, mas também pelos estudiosos 
e aqueles que se sentem autorizados a falar sobre os brasileiros descendentes de japoneses. Isso sem contar com a dimensão histórica que deve ser considerada.

Isso posto, este texto apresentará, primeiramente, uma breve contextualização da imigração japonesa ao Brasil ao longo do século XX. Em seguida, focará a presença de brasileiros no Japão, que foi se institucionalizando ao longo dos últimos vinte anos, no processo migratório internacional contemporâneo entre Brasil e Japão.

\section{Japoneses no Brasil}

A imigração de japoneses para o Brasil iniciou-se oficialmente em 1908, num período em que o Japão precisava escoar o excedente populacional e resolver seus problemas internos decorrentes da reforma política da Era Meiji - de 1868 a 1912, marcando o início da Era Moderna no Japão -, e quando o Brasil demandava por mão-de-obra imigrante.

Na virada do século XIX para o XX, o Brasil passou a adotar uma postura receptora de mão-de-obra imigrante, à medida que se sucedeu a abolição da escravatura e a implantação da cafeicultura demandava mão-de-obra nesse período. Mas em 1902, a Itália - de onde provinha o principal fluxo de imigrantes europeus ao Brasil nesse período - proibiu que seus cidadãos fossem recrutados e encaminhados ao Brasil. Para preencher essa lacuna, os japoneses foram considerados uma das alternativas, e a sua presença causou um acalorado debate sobre a sua aceitação no país. Esse período associava formulações sociológicas, de medicina social e políticas públicas na tentativa de explicar e resolver o atraso socioeconômico brasileiro. A fórmula combinava idéias de pensadores brasileiros e influências estrangeiras - como Gobineau, Lombroso, Nina Rodrigues, Paulo Prado, Manuel Bonfim, Oliveira Viana entre tantos outros (Schwarcz, 1993 ) - sobre o atraso socioeconômico do país, que foi sendo profundamente atrelado à presença negra na população brasileira. A preocupação era a do "branqueamento" da população, que assim justificava a procura de europeus brancos, como alemães e italianos (inicialmente) para atender a essa lógica. Era um período em que a elite brasileira estava preocupada em construir uma nação, com anseios eugênicos.

Os "amarelos", isto é, os asiáticos, não condiziam com os ideais da construção da identidade nacional brasileira, que era baseada na política de embranquecimento, embora eles tenham sido vistos como uma alternativa para compor a mão-de-obra e atender à demanda na lavoura cafeeira. Além disso, havia uma preocupação em relação à sua adaptação nas terras brasileiras. A questão da assimilação esperada pelos nacionais se contrapunha à racionalidade econômica e produtiva. Isso configurava uma das contradições da política imigratória brasileira, pois, ao receber os imigrantes, por um lado, desqualificava o nacional como trabalhador (uma vez que o trabalhador brasileiro era tido como indisciplinado e indolente), para justificar a imigração estrangeira, e, por outro, desqualificava

o imigrante como estrangeiro para justificar medidas discriminatórias (Vainer, 
1995). Pelo fato de o japonês não ser nem branco nem negro, os japoneses eram aqueles que não podiam achar facilmente o seu lugar no contexto brasileiro. Negros e brancos eram as duas pontas de uma tensa relação racial que atravessava as diversas naturezas das relações sociais estabelecidas no Brasil.

Nos alvores do século XX, a migração era uma questão diplomática prioritária para o seu Ministério das Relações Exteriores do Japão (MREJ). Segundo Shimizu (1998, p.78), o MREJ estava preocupado com as implicações negativas das práticas migratórias antijaponesas (nos países anglo-saxões, como Estados Unidos, Canadá e Austrália), que teriam peso simbólico no status do Japão como uma grande potência - status esse que foi adquirido e reconhecido internacionalmente ao vencer a guerra contra a China (1894-1895) e, em seguida, contra a Rússia (1904-1905). Assim, os oficiais do MREJ expressaram um interesse burocrático em resolver a questão da migração quando eles traçaram a "Proposta de igualdade racial" na Conferência de Paz de Paris em 1919. Embora as prioridades burocráticas do MREJ não necessariamente reflitam a visão de outras partes do governo nem da opinião pública, o MREJ acreditava, no entanto, que era uma prioridade urgente encontrar uma solução satisfatória ao tratamento discriminatório em relação aos imigrantes japoneses nos territórios anglo-saxões. Pois isso, simbolizava a posição inferior dos japoneses em relação a grandes potências ocidentais. Assim, a imigração refletia a insegurança do Japão de ser uma nação não-branca dentre as grandes potências - e os outros quatro eram ocidentais brancos (ibidem, p.87) .

Mais tarde, a campanha antijaponesa no Brasil foi, de um lado, alimentada pelo fato de o Japão ter se aliado ao Eixo na Segunda Guerra Mundial - isto é, pela crescente instabilidade internacional mediante a política militarista agressiva do Japão no continente asiático e o crescente poderio militar do nazi-fascismo na Europa, representado pela Alemanha e Itália -, e, de outro, os esforços nacionalistas brasileiros de construção de uma sociedade brasileira coesa, na qual todos os cidadãos, incluindo filhos de imigrantes das mais diferentes procedências, deveriam adotar uma consciência nacionalista brasileira.

Todo o processo de imigração e de estabelecimento desse contingente foi tutelado pelo governo japonês (Sakurai, 2000), desde recrutamento, propaganda, transporte, custeio, até o estabelecimento no país hospedeiro. O auge dessa imigração foi entre 1925 e 1934, com mais de 120 mil imigrantes. No Brasil, os anos 1930 foram marcados pelas mudanças políticas, com a implantação do Estado Novo, um período de ditadura com anseios nacionalistas, que restringiu drasticamente a entrada de estrangeiros no país.

Até eclodir a Segunda Guerra Mundial, os imigrantes japoneses no Brasil se consideravam nihonjin, isto é, japoneses, uma vez que ainda havia perspectiva de retornarem enriquecidos ao Japão. Depois desse evento, eles passaram a construir suas vidas nas terras brasileiras, distantes da possibilidade do retorno. Até o período da guerra, a permanência no Brasil era tida como provisória. A guerra foi utilizada como o fator decisivo para não ter que acionar o argumento do insucesso 


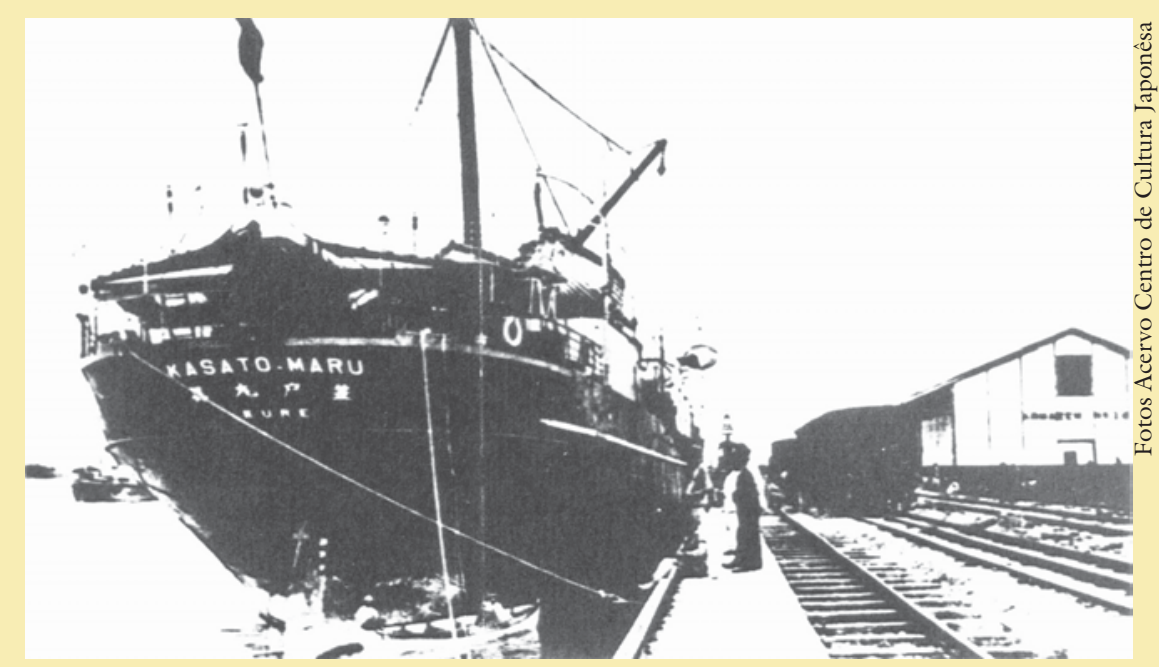

O vapor Kasato-Maru atracado no Porto de Santos, Cais 14.

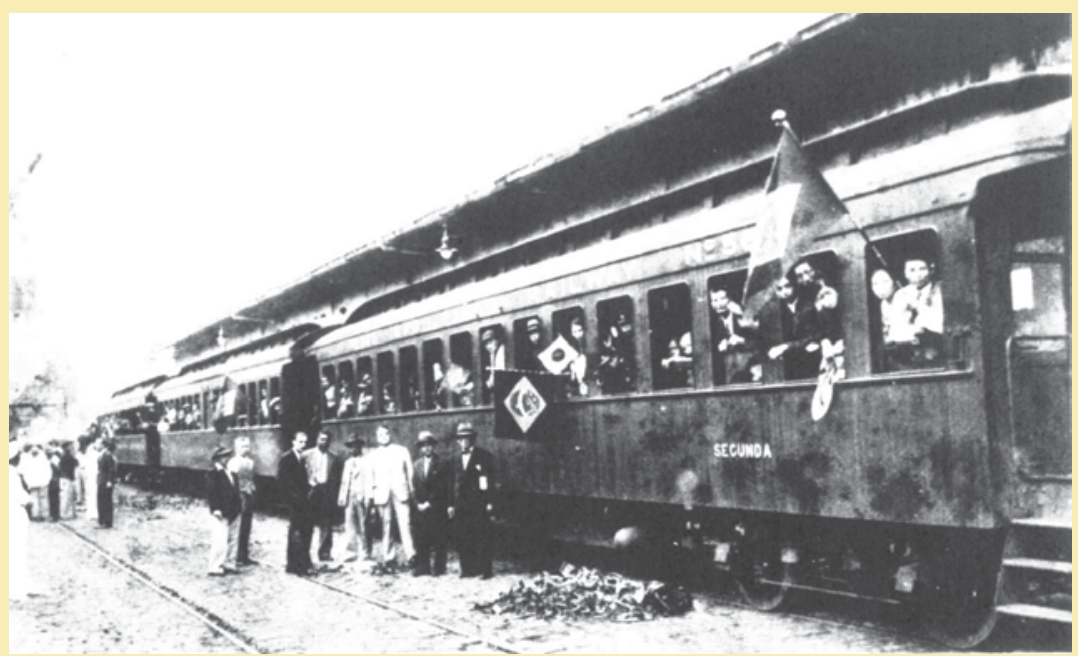

Na subida ao planalto paulista, a viagem de trem.

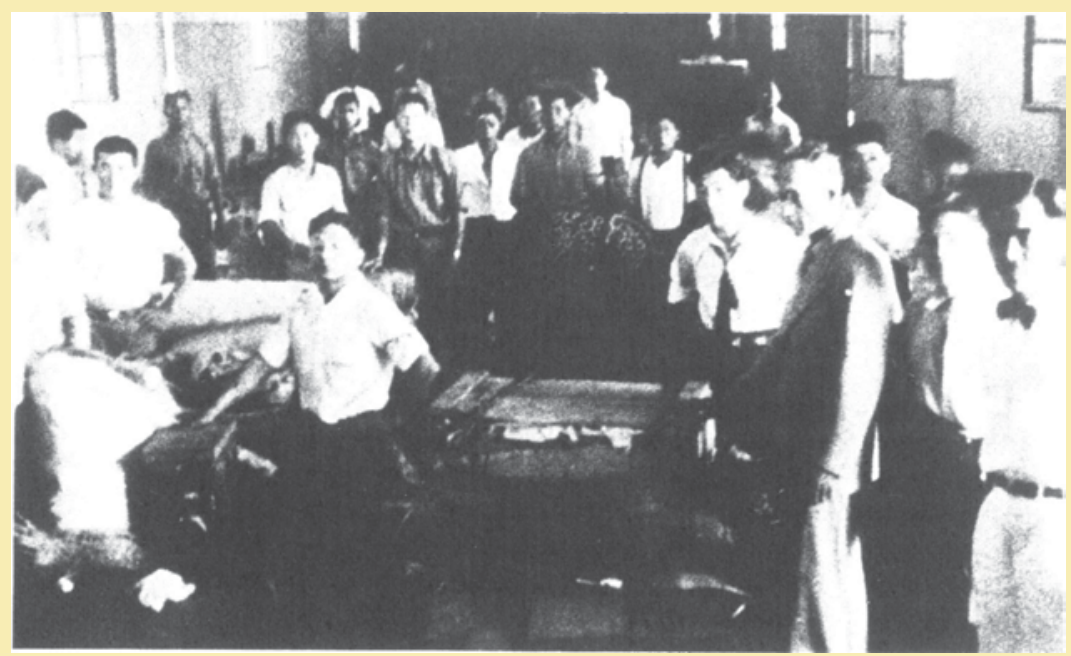

Os imigrantes com suas bagagens na hospedaria. 


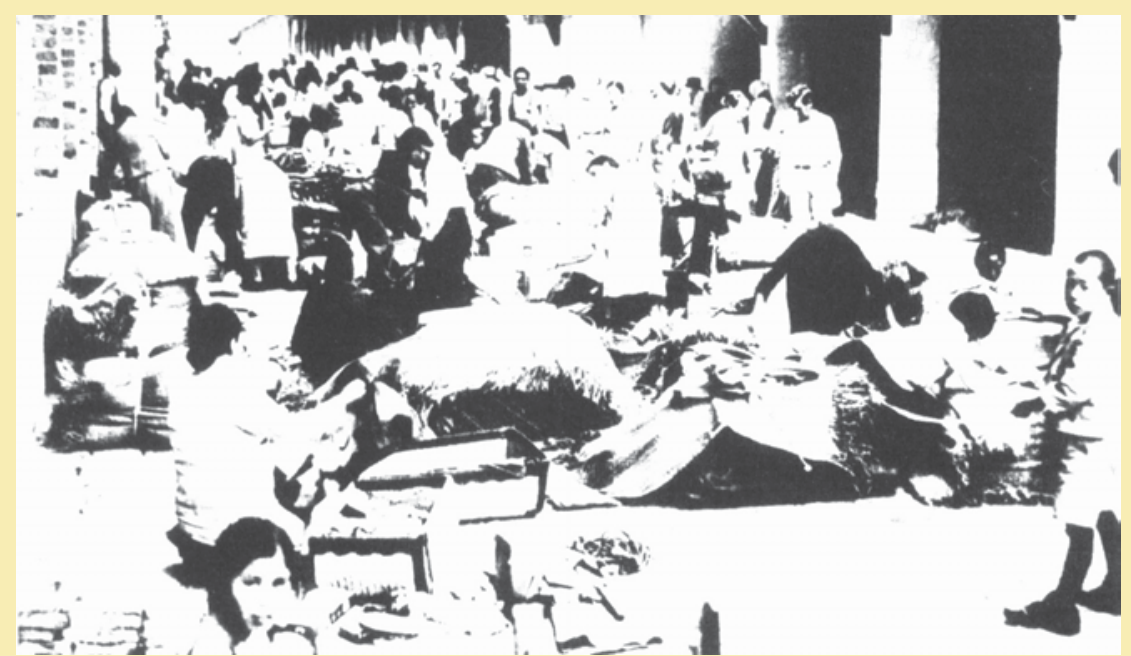

Os imigrantes preparando a partida para as fazendas.

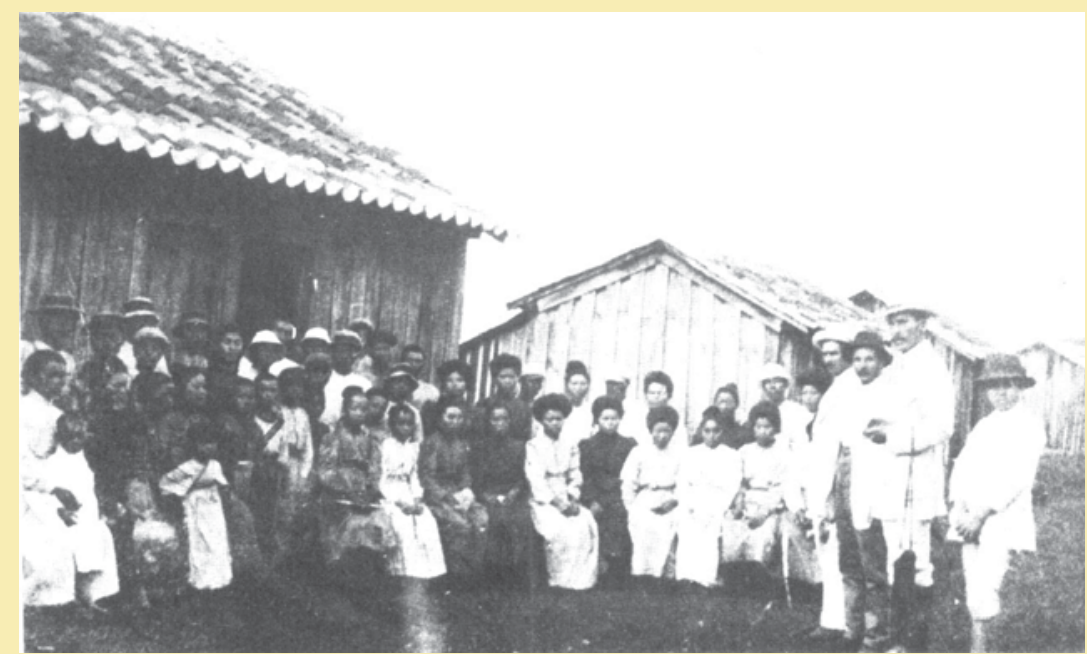

Os colonos japoneses na Fazenda Tibiriçá.

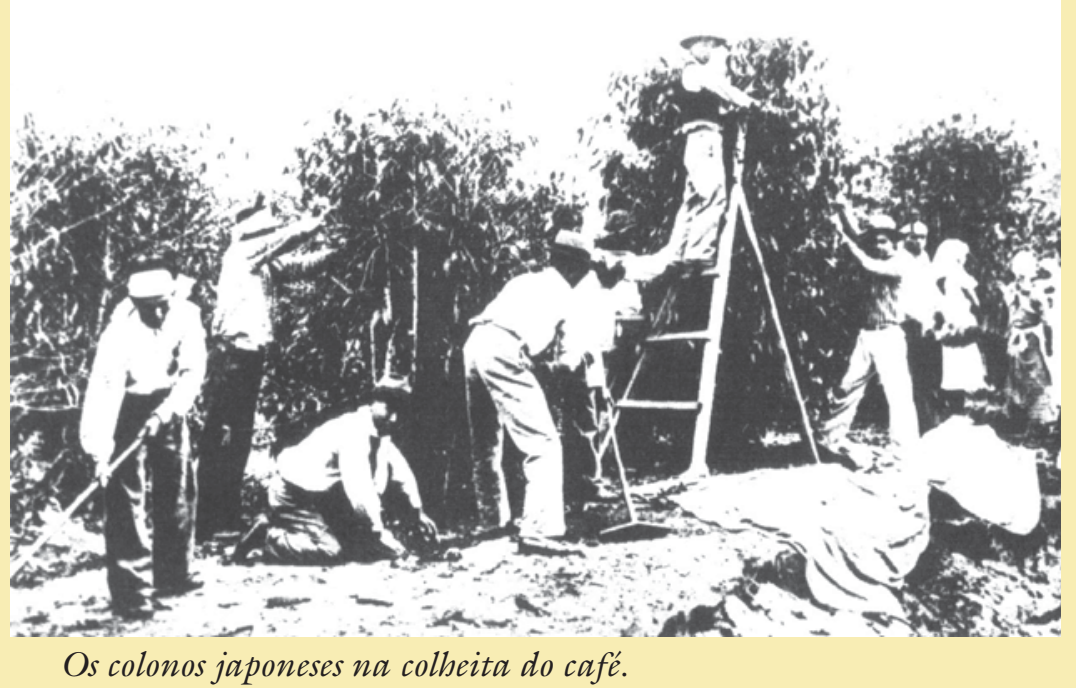


do não-retorno de quase todos os imigrantes. A fixação definitiva no Brasil, que vinha ocorrendo há pelo menos uma década, é finalmente incorporada e aceita. A guerra foi o pretexto simbólico para legitimar o processo, que era inexorável, da permanência definitiva no Brasil (Sakurai, 2000).

Após o período da Segunda Guerra Mundial, o fluxo de migrantes japoneses ao Brasil foi retomado em 1953. O governo japonês continuou regendo a migração, e pode-se dizer que os japoneses que imigraram ao Brasil no período pós-guerra eram diferentes dos que vieram no pré-guerra. Parece ter havido uma relação tensa entre os imigrantes japoneses do pré e os do pós-guerra. Os do pós-guerra - chamados de "Japão Novo" - eram jovens rapazes educados e especialistas qualificados na área agrícola e também em alguns setores da indústria. Houve, subseqüentemente, uma migração de noivas japonesas para se casarem com esses rapazes e se estabelecerem nas terras brasileiras. Nos anos 1960, o Japão começou a prosperar e diminuiu o fluxo migratório ao Brasil a partir desse período. Em 1973, encerrou-se o programa de emigração. O contingente japonês ao Brasil no período pós-guerra, entre 1953 e 1973, foi de aproximadamente 53 mil (CEHOAIJB, 1992, p.429).

A presença japonesa foi se institucionalizando ao longo do século XX, sobretudo no período pós-guerra, criando inúmeras entidades associativas: culturais, religiosas, esportivas, recreativas, agrícolas, por região de origem (províncias no Japão), por atividades ocupacionais etc., além da visibilidade nipônica nas comemorações decenais da imigração japonesa. A participação do governo japonês promovendo a imigração ao Brasil, em todos os aspectos, contribuiu para que os japoneses fossem fortemente associados às atividades agrícolas, representadas, por exemplo, pela Cooperativa Agrícola de Cotia (CAC - atualmente falida) e a alguns setores da indústria - como de sericicultura (criação de bicho-da-seda), algodão, siderúrgica e outros (Saito, 1980; CEHOAIJB, 1992).

Em relação à localização geográfica, pode-se dizer que os imigrantes japoneses se estabeleceram em vários núcleos coloniais, principalmente no Estado de São Paulo e no norte do Paraná, Mato Grosso do Sul, Pará e Amazonas. O Estado de São Paulo recebeu o maior contingente. Na capital paulista, os nipônicos instalaram-se ao redor da cidade e participaram ativamente da formação do Cinturão Verde, ou seja, do desenvolvimento da produção agrícola de legumes, verduras e frutas para abastecer a Região Metropolitana de São Paulo. Instalaram-se, também, em vários bairros paulistanos, destacando-se os bairros da Liberdade e de Pinheiros. Ainda no Estado de São Paulo, os emigrantes japoneses fixaram-se na região Alta Paulista - como Tupã, Bastos, Marília, entre outros municípios - onde desenvolveram a agricultura do algodão. Nas zonas alagadiças do Vale do Paraíba (entre São Paulo e Rio de Janeiro), desenvolveram a cultura do arroz. No Vale do Ribeira, Iguape, litoral sul do Estado de São Paulo, introduziram a cultura do chá. No Estado do Pará, na região de Bragança e em Tomé-Açu, cultivam a pimenta-do-reino. No Amazonas desenvolveram a cultura de várzea, destacando-se a juta e o arroz. 
Atualmente, no início do século XXI, a vaga estimativa de japoneses e seus descendentes presentes no Brasil é em torno de 1,3 milhão (Jica, 2003), e 80\% de japoneses e brasileiros de origem japonesa (incluindo os japoneses naturalizados) devem estar localizados no Estado de São Paulo; dentre esses, a maior parte deve estar presente na Região Metropolitana de São Paulo, 15\% no Paraná (principalmente na região norte) e os $5 \%$ restantes devem estar espalhados por quase todos os outros estados brasileiros. ${ }^{2}$

\section{Brasileiros no Japão}

Nos anos 1980, o Brasil atravessou um período de crise econômica com altas taxas de inflação, assim como frustrações no aspecto político no processo de redemocratização. Essa situação fez que um grande contingente de brasileiros da classe média buscasse alternativas no exterior como trabalhadores migrantes de baixa qualificação, principalmente nos Estados Unidos, no Paraguai, no Japão e na Europa (Assis \& Sasaki, 2000). A partir da segunda metade da década de 1980, o volume desse contingente se massificou. Nos primeiros anos do terceiro milênio, a estimativa do volume de brasileiros no exterior gira em torno de três milhões (CRER, ABA, 2003).

As primeiras notícias sobre a ida de brasileiros nipo-descendentes para trabalhar temporariamente no Japão apareceram nos meados da década de 1980, apresentando um movimento tímido quanto ao volume. Em geral, eles não tiveram grandes problemas burocráticos para entrar no território japonês, pois tinham origem japonesa; eram das primeiras gerações - issei (primeira geração ou os próprios japoneses nascidos no Japão) e/ou nissei (segunda geração ou os filhos dos migrantes japoneses nascidos fora do Japão) -, logo, muitos tinham nacionalidade japonesa ou dupla nacionalidade (podendo ingressar no Japão como japoneses $^{3}$ ); grosso modo, eram homens de idade avançada; chefes de família; casados; sabiam falar japonês e tinham pretensões de estada temporária no Japão (Sasaki, 1999).

Enquanto no Brasil, a década de 1980 foi caracterizada pela recessão econômica, inflação e desemprego, do outro lado do planeta, o Japão experimentava um boom econômico durante a segunda metade dessa década. As pequenas e médias empresas demandavam mão-de-obra estrangeira - o que influenciava em toda a economia japonesa, porque no final da cadeia produtiva encontravam-se as pequenas firmas, que recebiam encomendas das grandes empresas montadoras por meio do sistema de subcontratação. Como nessas pequenas empresas não havia perspectiva de carreira ou ascensão profissional, os japoneses - sobretudo os mais jovens, escolarizados, que ingressavam no mercado de trabalho - recusavam-se a trabalhar nelas, por não as considerarem oportunidades viáveis de ascensão ou mobilidade social, preferindo as empresas maiores, mais competitivas, porém com maior possibilidade de ascensão profissional. Isso sem contar com o fato de o Japão estar sofrendo com a questão demográfica, tendo uma população idosa cada vez mais numerosa, associada à baixa natalidade. Assim, muitas des- 
sas pequenas empresas faliram por falta de mão-de-obra e porque a maioria dos empregados tinha uma idade média alta, na faixa dos quarenta a cinqüenta anos. Não conseguindo atrair os empregados japoneses, as pequenas empresas começaram a contar com os trabalhadores estrangeiros que aceitassem trabalhar.

Houve então um grande crescimento de residentes estrangeiros ilegais. A maioria era proveniente dos países asiáticos, como Coréia do Sul, China, Bangladesh, Filipinas, Paquistão e Tailândia. Em geral, esses migrantes ilegais eram homens que se dirigiam aos setores de construção e manufatureiro, e grande parte das mulheres imigrantes ilegais apreendidas era empregada como bar hostesses e entertainers recrutadas pela "indústria do sexo" (Morita \& Sassen, 1994, p.154).

Diante desses números de ilegais, houve a reforma da Lei de Controle da Imigração do Japão, promulgada em junho de 1990, implementando uma política imigratória mais restritiva, incluindo sanções aos empregadores de trabalhadores estrangeiros ilegais, assim como aos intermediários ou contratadores que sempre recrutaram trabalhadores para as firmas japonesas. Apesar de todo esse esforço, na prática, poucos empregadores foram penalizados por violação à nova Lei de Imigração (Cornelius, 1995). Diante da implementação de uma política imigratória mais restritiva, e uma vez que o mercado japonês estava tendo sérios problemas com a falta de mão-de-obra em setores de manufatura, esses empregadores - não apenas de firmas pequenas, mas também das grandes empresas - substituíram gradualmente os trabalhadores ilegais por trabalhadores descendentes de japoneses provenientes da América do Sul (Yamanaka, 1996; Komai, 1992, apud Morita \& Sassen, 1994, p.162), principalmente brasileiros e peruanos. Segundo Cornelius (1995, p.396), a política de oportunidades de imigração facilitada para os nikkeijins da América Latina ${ }^{4}$ é vista pelas autoridades japonesas como um meio, politicamente de baixo custo, de ajudar a resolver a falta de mão-de-obra, com a vantagem adicional de que os imigrantes com ancestralidade japonesa não são vistos a perturbar a homogeneidade étnica mítica do país.

Dessa maneira, os migrantes nipo-brasileiros de até a terceira geração (netos de japoneses) têm um acesso facilitado, dada a sua origem étnica, nacional e sua correspondente consangüinidade, com a possibilidade de exercer atividades remuneradas no Japão sem restrições de renovar o visto e de vir a ser residentes permanentes.

A presença brasileira começou então a se institucionalizar e se consolidar no Japão, principalmente a partir dos meados dos anos 1990, entrando em cena novos ou certos atores sociais, como os candidatos a trabalhadores migrantes, as pequenas empresas japonesas demandando mão-de-obra estrangeira e os agentes intermediários.

\section{Intermediários}

Esses agentes intermediários de recrutamento não são apenas as lojas de turismo que vendem passagens aéreas, mas também podem ser alguns agencia- 
dores informais que ganham comissão ou quantia em dinheiro para recrutar e enviar ao Japão trabalhadores migrantes. Em geral, essas pessoas têm forte vínculo com a comunidade japonesa no Brasil e são ligadas às empreiteiras de mão-de-obra no Japão, ou mesmo às próprias empresas que demandam trabalhadores. Na maior parte das vezes, quando uma fábrica precisa de trabalhadores, a empreiteira - uma firma que oferece serviço terceirizado de recursos humanos - é acionada e envia as propostas à agência brasileira, que, por sua vez, recruta os candidatos a trabalhadores migrantes, de acordo com os requisitos dos empregadores.

Isso, entretanto, não descarta a participação dos familiares e dos conhecidos nesse empreendimento, pois, mesmo aqueles(as) que não migram de fato, isto é, aqueles(as) que permanecem na origem, também participam do processo migratório - por exemplo, cuidando da casa e da família, administrando as remessas de dinheiro enviadas, rearranjando a organização do domicílio, articulando novas e velhas relações. Se na origem os migrantes contam com a ajuda financeira de parentes, no destino, esses também têm um papel significativo. São importantes para fornecer "ajuda" como hospedagem e para cuidar de crianças, embora a participação dos agentes intermediários ou recrutadores seja ainda bastante marcante no processo migratório de brasileiros ao Japão. As agências de recrutamentos legais e ilegais têm determinado os destinos, ocupações e a moradia, embora os migrantes possam escolher onde trabalhar antes de partir ao Japão.

Provavelmente, essas agências começaram a surgir no final da década de 1980, quando alguns da primeira geração de migrantes brasileiros no Japão possivelmente tornaram-se intermediários - nas tarefas corriqueiras de providenciar vistos, documentos relativos a contratos, moradias etc. - a partir do know-how adquirido com suas próprias experiências como trabalhadores migrantes. Assim, os imigrantes mais antigos ou experientes passaram a ter outras ocupações, como de intermediação, recrutando novos migrantes. Podemos dizer, então, grosso modo, que muitos intermediários de hoje foram os migrantes experientes de ontem. Esse quadro não é exclusivo dos brasileiros no Japão, sendo recorrente nos diversos fluxos migratórios, internacional ou interno, com diversas nacionalidades e períodos.

Antes de realizar a pesquisa de campo no Brasil e no Japão, uma das minhas hipóteses iniciais era de que, ao longo do processo migratório, os agentes intermediários de recrutamento de trabalhadores migrantes brasileiros iriam perdendo sua força e importância, à medida que contassem com apoio e ajuda de seus parentes, familiares e amigos para o empreendimento migratório. Mas, na pesquisa de campo realizada na cidade de Maringá (PR), ${ }^{5}$ os resultados preliminares indicaram que cerca de $70 \%$ dos nipo-brasileiros de Maringá vão ao Japão por intermédio de uma agência de viagens e de recrutamento. A despeito disso, os maringaenses vão para diversas cidades de destino no Japão, não se concentrando em nenhuma região específica (onde pudessem ter parentes e amigos já estabelecidos), mas sim onde estão os empregos. 


\section{Institucionalização da presença brasileira no Japão}

Concomitantemente, com o intuito de amparar os trabalhadores migrantes, também começaram a surgir centros de atendimento, informação, orientação e apoio aos trabalhadores migrantes, de iniciativa governamental, municipal e de vários grupos de voluntários sem fins lucrativos. Um exemplo disso é o Centro de Informação e Apoio ao Trabalhador no Exterior (Ciate), criado em São Paulo (Brasil). De acordo com Ricardo Sasaki (2002, p.254-5), esse Centro

fornece informações e orientações sobre ofertas de emprego no Japão; a cultura, os usos e costumes, e a vida cotidiana no Japão; legislação trabalhista japonesa; assessoria jurídica; sistema educacional no Japão; seguro social (saúde, aposentadoria, desemprego, acidentes de trabalho) japonês; restituição de aposentadoria e solicitação de pensão; imposto de renda (bitributação) e demais tributos no Japão.

No Japão, há mais de seiscentas entidades similares, principalmente onde há significativa presença de brasileiros, assim como estrangeiros de outras nacionalidades na condição de trabalhador migrante. Em geral, essas entidades podem estar vinculadas à prefeitura local, às associações civis, regionais e locais, grupos voluntários que oferecem informações e orientações de diversas naturezas - trabalhista, jurídica, educacional, cultural, social, ensino de língua, cotidiana (como coleta de lixo) etc.

$\mathrm{Na}$ sociedade receptora, começaram a surgir notícias de restaurantes e lojas de produtos brasileiros atendendo o público consumidor especialmente brasileiro (Kawamura, 2003). São pequenos negócios de brasileiros para brasileiros. A imprensa étnica voltada para os nipo-brasileiros no Japão, como jornais e revistas em língua portuguesa, passaram a aparecer, com distribuição nos dois países, como os jornais International Press, Jornal Tudo Bem, Nova Visão, Folha Mundial (Ishi, 2003). Sob diferentes aspectos, portanto, desencadeou-se um processo de institucionalização do movimento de deslocamento entre Brasil e Japão, compondo e consolidando redes migratórias cada vez mais complexas.

A década de 1990 começou a registrar o aumento no volume de migrantes com várias idas e vindas entre o Japão e o Brasil, sendo facilitadas ainda mais pelo visto de reentrada no Japão (promulgada na Reforma de 1990), dispensando os trâmites burocráticos. Muitos retornavam ao Brasil apenas por alguns meses para "férias" do trabalho, com passagem marcada para o Japão e continuar no mesmo emprego.

Acompanhando o fluxo do movimento migratório desse contingente, notamos uma mudança no perfil dos brasileiros no Japão: gerações mais avançadas (segunda [nissei] e terceira [sansei]); proporção sexual relativamente equiparada; faixa etária mais jovem; sem o domínio da língua (dada a grande presença de brasileiros no Japão, diminui a necessidade de os novos migrantes saberem falar a língua japonesa); mais solteiros e recém-casados (casados há pouco tempo ou com filhos pequenos e/ou dependentes) entre os brasileiros no Japão (não significando necessariamente apenas esses, isto é, casando-se também com cônjuges 


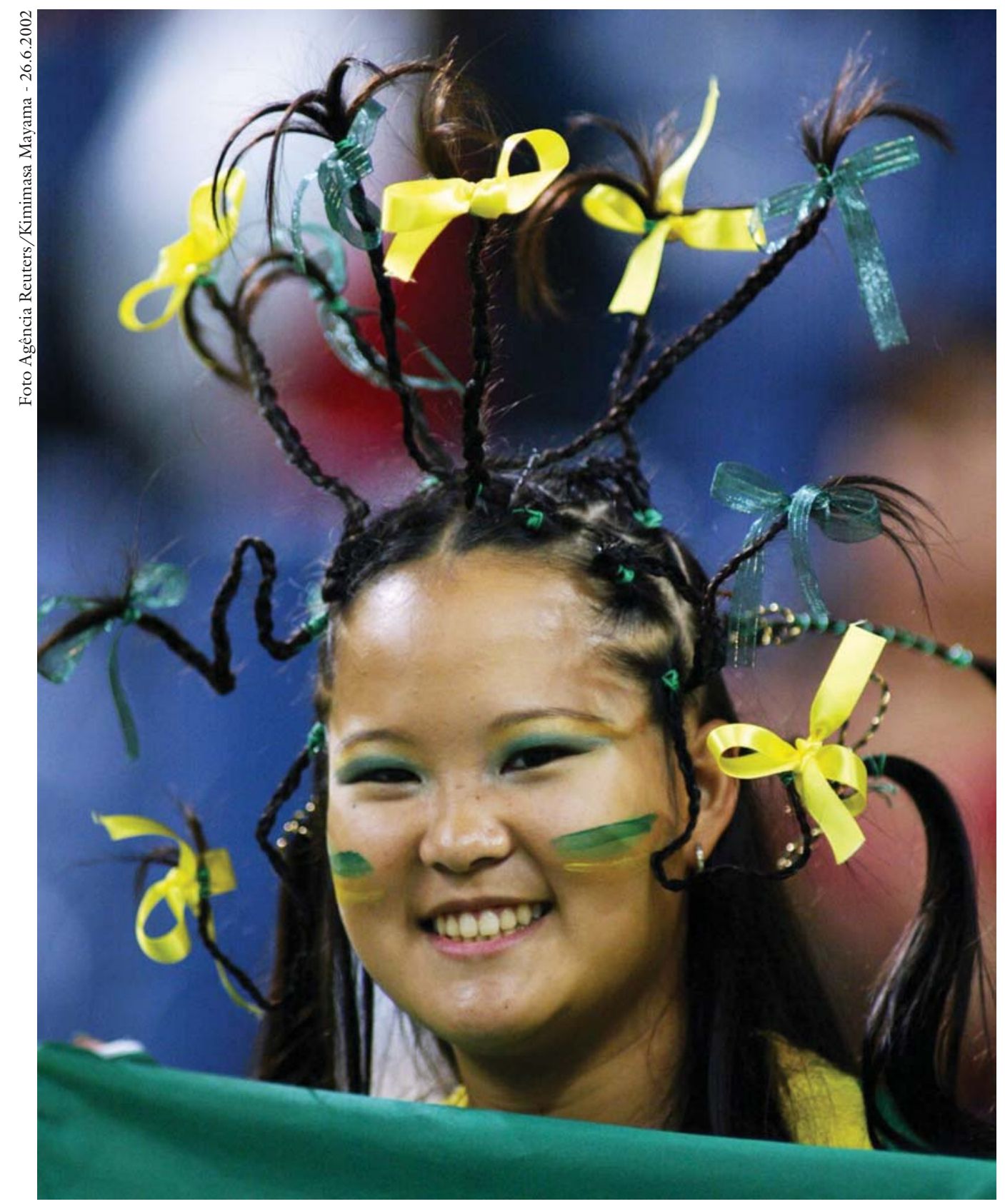

Semifinal da Copa de 2002: Brasil x Turquia, no estádio da Província de Saitama, no Japão.

japoneses); caráter mais familiar do que individual; aumento na duração da estada dos brasileiros no Japão; presença de pessoas de origem não-nipônica entre os cônjuges dos descendentes de japoneses que têm direitos estendidos, isto é, aqueles que não têm ancestralidade japonesa passam a ter os mesmos direitos que os cônjuges de origem nipônica e são igualmente classificados como nikkeijin.

As cidades onde mais se concentram brasileiros são Hamamatsu (Shizuoka), onde, em 2000, havia mais de onze mil brasileiros e, em 2004, aumentou para 13,8 mil (Japan Immigration Association, 2005). As quatro cidades seguintes são 


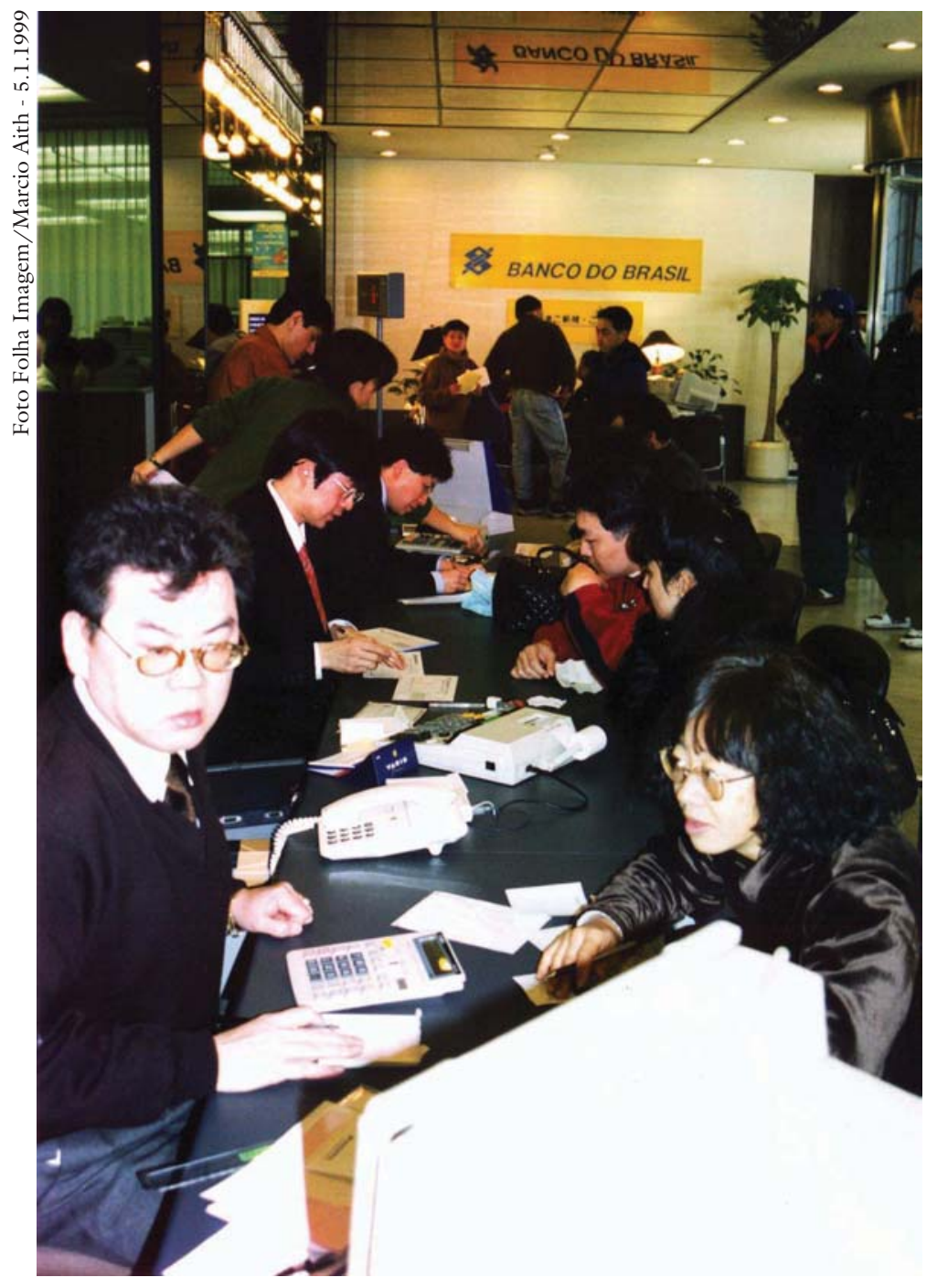

Imigrantes brasileiros no Japão enviam dinbeiro para o pais através de agência do Banco do Brasil, em Tóquio.

todas da província de Aichi - Toyohashi, Toyota, Nagoya e Okazaki -, onde predominam a indústria automobilística e as firmas subcontratadas que alimentam a produção em cadeia desse setor nessa região. É também onde se encontra a preocupação por parte do governo local em promover uma política de integração dos estrangeiros para a vida comunitária local ou regional. Os brasileiros se encontram concentrados na região central do Japão, como Aichi, Shizuoka, Kanagawa, Saitama e Gunma, onde, juntas, abrigam mais da metade de toda a população brasileira presente no Japão.

Mas eles também se encontram em diversas outras localidades. Isso deve estar relacionado com o fato de haver empregos em outros setores, como o de serviços, alimentícios (frigoríficos, supermercados, panificação, marmitas etc.). Nesse sentido, podemos dizer que, embora os brasileiros ainda sejam alocados principalmente no setor manufatureiro (automobilístico, eletrônicos etc.), ao longo do tempo eles têm ocupado empregos nos outros setores citados. Pode-se dizer que 
o seu deslocamento geográfico está muito mais ligado à mudança de emprego e/ou melhor salário do que a outros motivos - por exemplo, reunião familiar - e que, por sua vez, está nas mãos das empreiteiras às quais estão vinculados.

Nagano é uma das províncias que chamam atenção no que se refere à presença brasileira crescente em seu território. Se em 1994 Nagano foi a sétima província que mais recebeu brasileiros, com pouco mais de $6,5 \mathrm{mil}$, ao longo dos anos 1990, ela foi recebendo cada vez mais brasileiro, e em 1998 ela passou a ser a terceira província com maior presença brasileira (com 14.670), depois de Aichi (quase 41 mil) e Shizuoka (mais de 31 mil) (Japan Immigration Association, 2005). A partir desse ano, Nagano permanece como a terceira província com mais brasileiros. Isso se deve ao fato de que nessa região há indústrias de componentes eletrônicos, que também passaram a contar com a mão-de-obra estrangeira na sua produção. Já em Aichi e Shizuoka, encontram-se as indústrias manufatureiras, sobretudo do setor automobilístico.

Moradia, educação dos filhos de brasileiros migrantes ${ }^{6}$ e saúde ${ }^{7}$ são alguns dos assuntos que têm sido alvo de atenção. Comparando com o governo central, os governos locais têm inovado suas políticas para acomodar os residentes estrangeiros. Nesse sentido, muitos governos locais têm instaurado assembléia para os cidadãos estrangeiros ou reuniões similares nos últimos anos (Ikegami, 2001; Pak, 2001). Essas respostas administrativas em âmbito local também refletem uma velha reivindicação por parte dos coreanos que buscam ser reconhecidos como membros da comunidade local sem considerar sua nacionalidade.

\section{"A volta dos que nãa foram"}

Muitas vezes, esse recente fluxo de brasileiros ao Japão é tratado como uma "migração de retorno" (Koyama, 1998; Tsuda, 1999, 2000a, 2000b, 2003; Yamanaka, 1996, 1997). Entretanto, a experiência migratória dos brasileiros que estão indo para o Japão nas últimas décadas do século XX é diferente da dos japoneses que imigraram para o Brasil no início do mesmo século. Sim, eles são descendentes dos imigrantes japoneses, mas o contexto é bastante distinto. Poderíamos dizer que seria "a volta dos que não foram", pois, embora os brasileiros que migram para o Japão sejam descendentes de imigrantes japoneses que no início do século XX vieram para o Brasil, muitos deles, entretanto, nunca estiveram antes na Terra do Sol nascente. Como poderiam então retornar de onde nunca partiram?

Se pensarmos em relação a uma ideologia adotada pelo governo japonês, aí, sim, o uso desse termo é bastante justificável, e de fato bastante explorado para atender aos seus valores ideológicos conservadores. É uma população que atende às necessidades raciais e ideológicas do governo japonês e, ao mesmo tempo, atende às demandas do mercado de trabalho por mão-de-obra barata e não-qualificada. É uma população que ainda não causa problemas, mas não seria de admirar se num futuro próximo a conveniência tenha sua validade vencida e ter que ser novamente rearticulada. Mas, para qualificar a migração como 
de "retorno", é preciso atentar às implicações de seu uso. O problema não é utilizar o termo, mas, sim, ter clareza ou ter consciência dos fatores que estão por trás. Por exemplo, a manipulação ideológica do governo japonês em nome da identidade nacional nipônica que se pode notar em várias dimensões da vida social. Enfim, são circunstâncias que impõem a rediscussão de paradigmas de identidade e referenciais étnicos, especialmente na sociedade japonesa.

No Japão, o requisito burocrático fundamental para exercer atividades remuneradas de trabalho é ter "origem japonesa", como vimos anteriormente. Esses migrantes brasileiros de que falamos se enquadram nessa categoria de $n i$ kkeijin (descendentes de japoneses), embora sejam classificados nas atividades cotidianas como "estrangeiros", ao lado de outros grupos populacionais como coreanos, chineses e filipinos, que, por sua vez, têm outros históricos de inserção na sociedade receptora. Além disso, o brasileiro é classificado como um trabalhador migrante de baixa qualificação e o seu trânsito na estrutura ocupacional japonesa é bastante restrito. A ascendência nipônica é um quesito importante para fins burocráticos - como obtenção de visto de entrada - e ideológicos japoneses, mas, na vida cotidiana, mergulha numa outra dimensão de relações com diversas alteridades.

Ambigüidade é o signo que marca o período em que o Japão experimenta neste início do terceiro milênio o gosto da pós-modernidade, com excesso de informações e de velocidade, nesse processo de internacionalização. A presença de estrangeiros num país em que ainda vigora a idéia de uma homogeneidade mítica de seu povo obriga a repensar sobre a sua própria sociedade. A imagem refletida no espelho distorcido nem sempre é eloqüente, fácil de se olhar. Receber em seu país aqueles nikkeijin - que não era bem assim que tinha imaginado antes do encontro (com seus colegas japoneses) no chão de fábrica - mas com a cara e o documento que atestam a consangüinidade e que dizem ser os descendentes de origem japoneses residentes no exterior - faz voltar a atenção à sua própria história e à história da sua relação com o Brasil ao longo do século XX. O que se transformou ao longo desse tempo entre esses dois espaços? Não dá para esperar que sejam a mesma coisa. Enquanto as pessoas experimentam o deslocamento espacial, social, cultural e simbólico, a percepção do tempo mudou drasticamente, se compararmos o início e o fim do século XX. É a tal da compressão do tempo e do espaço (Harvey, 1993). Há, quando não deveria haver, surpresa em colocar lado a lado o japonês imigrante no Brasil do início do século XX e o japonês receptor de brasileiros no Japão no final do mesmo século. Enquanto isso, os brasileiros descendentes de japoneses transitam entre esses dois espaços geográficos, sociais, culturais e simbólicos.

\section{Notas}

1 A pesquisa foi financiada pela Fundação de Amparo à Pesquisa do Estado de São Paulo (Fapesp). 
2 Estimativa baseada na lista de entidades de origem japonesa, levantada pelo Museu Histórico de Imigração Japonesa no Brasil (1999).

3 A estimativa apresentada por Ricardo Sasaki (2002) indica que cerca de 26 mil sejam cidadãos que possuem dupla nacionalidade. De qualquer forma, temos o levantamento do Ministério das Relações Exteriores do Japão. Segundo esses dados, estima-se que, no ano de 2003, mais de 911 mil japoneses residiam no exterior, sem contar com mais de 291 mil expatriados permanentes, que juntos totalizavam pouco mais de 1,2 milhão. Disponível em: <http://www.stat.go.jp/data/nenkan/zuhyou/y0215000.xls]>. Consultado em: 4.3.2006.

4 São japoneses ou seus os descendentes nascidos e residentes fora do Japão, não se restringindo apenas aos brasileiros.

5 Os dados nos quais me baseio aqui são resultados da pesquisa de campo realizada em Maringá, no primeiro semestre de 2001, que fez parte do projeto coletivo coordenado pela Profa. Dra. Teresa Sales, sobre "Redes sociais nas migrações internacionais: os migrantes brasileiros para os Estados Unidos e o Japão" (Fapesp; Nepo-Unicamp, 2001). Maringá se situa na região norte do Estado do Paraná, na Região Sul do Brasil. Nessa cidade de 288 mil habitantes, 15 mil ou cerca de $5 \%$ são japoneses e seus descendentes presentes nessa cidade, em 2000, segundo o censo demográfico do IBGE.

6 Sobre educação das crianças brasileiras no Japão (inclusive questão do bilingüismo e multiculturalismo), ver, por exemplo: Imazu (2000, 2001), Imazu \& Matsumoto (2001), Matsuzake (2002), Nishihara (1996), Öta (2000), Shiroma (1990, 1993), Takahashi (2001), Yamawaki (2003), Yoshioka (2001) e Nakagawa (2001).

7 Sobre moradia, convivência cotidiana e saúde, ver Ikegami (2001), Miyasaka (2002), Nakagawa (2001) e Yoshino (1997).

Referências bibliográficas

ASSIS, G. de O.; SASAKI, E. M. Novos migrantes do e para o Brasil: um balanço da produção bibliográfica. In: CASTRO, M. G. (Coord.) Migrações internacionais: contribuições para políticas, Brasil 2000. Brasília: Comissão Nacional de População e Desenvolvimento, 2001. p.615-69.

CEHOAIJB - Comissão de Elaboração da História dos 80 Anos da Imigração Japonesa no Brasil. Uma epopéia moderna - 80 anos da imigração japonesa no Brasil. São Paulo: Hucitec, Sociedade Brasileira de Cultura Japonesa, 1992.

CORNELIUS, W. Japan: The Illusion of Immigrant Control. In: CORNELIUS, W.; MARTIN, P. L.; HOLLIFIELD, J. F. (Ed.) Controlling Immigration - A Global Perspective. Stanford (California): Stanford University Press, 1995. p.375-414.

CRER, ABA - Comissão de Relações Étnicas e Raciais, da Associação Brasileira de Antropologia. Documento ABA CRER - abril de 2003. Disponível em: <http://www. abant.org.br/conteudo.php?exibir=79>. Acessado em: 22.4.2003.

HARVEY, D. A condição pós-moderna. São Paulo: Loyola, 1993.

IKEGAMI, S. (Ed.) Burajirujin to Kokusaika suru Chiiki Shakai - Kyoju, Kyõiku, Iryõ. [O brasileiro e a comunidade local que se internacionaliza - Moradia, educação, Saúde]. Tokyo: Akashi Shõten, 2001. 
IMAZU, K. (Ed.) Chiiki Shakai no Kokusaika to Kyõiku no Shokadai [Pesquisa em curso sobre a internacionalização da comunidade regional e educação]. Nagoya Daigaku Daigakuin Kyõiku Shakaigaku Kenkyu Shitsu [Centro de Pesquisa em Sociologia da Educação da Universidade de Nagoya]. Imazu Zemi, Ripõto Shiriizu [Seminários do Prof. Imazu, Série de Relatórios de Pesquisa] n.1, março 2000.

(Ed.) Gaikokujin Jidõ Seito Kyõiku no Shokadai [Pesquisa em curso sobre a educação de estudantes filhos de estrangeiros]. Nagoya Daigaku Daigakuin Kyõiku Shakaigaku Kenkyu shitsu [Centro de Pesquisa em Sociologia da Educação da Universidade de Nagoya] Imazu Zemi, Ripõto Shiriizu [Seminários do Prof. Imazu, Série de Relatórios de Pesquisa] n.2, março 2001.

IMAZU, K.; MATSUMOTO, K. Tokai Chiiki no Shinrai Gaikokujin Gakkõ [Escolas para os Estrangeiros Recém-Chegados na Região de Tokai]. Nagoya Daigaku Daigakuin Kyõiku Shakaigaku Kenkyu shitsu [Centro de Pesquisa em Sociologia da Educação da Universidade de Nagoya]. Imazu Zemi, Ripõto Shiriizu Seminários do Prof. Imazu, Série de Relatórios de Pesquisa] n.3, março 2001.

ISHI, A. Making History, Reinterpreting Experience: The Ethnic Media among Brazilians in Japan. In: YAMADA, M. (Org.) Emigración latinoamericana: comparación interregional entre América del Norte, Europa y Japón. JCAS Symposium Series n.19; Population Moviment in the Modern World, n.7. Osaka: Japan Center for Area Studies (JCAS), National Museum of Ethnology, 2003. p.473-90.

JAPAN IMMIGRATION ASSOCIATION [Zaidan Hõnin Nyukan Kyõkai], Zairyu Gaikokujin Tõkei [Estatísticas sobre estrangeiros residentes no Japão (Relatórios Anuais)]. 1995 a 2005

JICA (Japan International Cooperation Agency). Os nikkeis e a sociedade brasileira nos próximos 20 anos. São Paulo: Jica, 2003.

KAWAMURA, L. Para onde vão os brasileiros? Imigrantes brasileiros no Japão. 2.ed. rev. Campinas: Ed. Unicamp, 2003.

KITAGAWA, T. Gunma-ken Oizumi-machi ni Okeru Nikkeijin Hiaringu Chõsa: Eijuka Shikõ to Ikeire Kibanseibi [Pesquisa interrogatória de trabalhadores nikkeis em Oizumi-machi, na provínicia de Gunma: a intenção de se tornar permanente e a estrutura fundamental para sua aceitação]. In: Hito no Kokusaika ni Kansuru Sõgoteki Kenkyu: Tokuni Gaikokujin Rõdõsha ni Kansuru Chõsa Kenkyu o Chushin ni [Pesquisa Geral sobre a Internacionalização das Pessoas: Foco especial sobre a Pesquisa sobre Trabalhadores Estrangeiros]. Tokyo: Tõyõ University, 1992. p.89-154.

KOMAI, H. Are Foreign Trainees in Japan Disguised Cheap Labores? Migration World, v.20, p.13-17, 1992.

. Migrant Workers in Japan. London \& New York: Kegan Paul International.

KOYAMA, C. Return Migration of Japanese-Brazilians: The Transformation of Ethnic Identity in the Company of their Ancestors. 1998. Dissertação (Mestrado) - University of Florida.

LINGER, D. T. No One Home - Brazilian Selves Remade in Japan. Stanford, California: Stanford University Press, 2001.

MATSUZAKE, C. S. Zainichi 10dai Burajirujin no Oyako no Komyunikeshon - Gengo to Kokoro no Mondai [A comunicação entre pais e filhos de brasileiros residentes no Japão 
- Questão de linguagem e de sentimento]. Seisaku Kenkyu Daigakuin Daigaku, Kokusai Kõryu Kikin, Kokuritsu Kokugo Kenkyu-jo Renkei Daigakuin Shushikatei Tokutei Kadai Kenkyu [Pós-graduação em Política, Fundação Japão, Centro de Pesquisa Nacional de Língua Japonesa, Pesquisa do Curso de Mestrado da Faculdade Renkei], 2002.

MIYASAKA, L. S. et al. Mental Health of Two Communities of Japanese-Brazilians: A Comparative Study in Japan and in Brazil. Psychiatry and Clinical Neurosciences, v.56, p.1-55, 2002.

MORITA, K.; SASSEN, S. The New Illegal Immigration in Japan, 1980-1992. International Migration Review, v.28, n.1, p.153-63, Spring 1994.

NAKAGAWA, D. I. Contribuição ao estudo da saúde mental no desenvolvimento dos trabalhadores brasileiros no Japão. In: SOCIEDADE DOS CONSULTORES. (Org.) Anais do Simpósio "15 anos do movimento dekassegui: desafios e perspectivas". São Paulo, 2001. p.97-100.

NAKAGAWA, K. Y. Crianças envolvidas no movimento dekassegui. São Paulo, 2001. Dissertação (Mestrado em Serviço Social) - Pontifícia Universidade Católica.

NISHIHARA, R. Gaikokujin Jidõ Seito no tame no Nihongo Kyõiku no Arikata. [Procedimento para ensinar língua japonesa para estudantes, filhos de estrangeiros]. Nihongogaku 2go [Estudos da Língua Japonesa n. 2]. Meiji Shoin, 1996.

ÕTA, H. New Comer no Kodomo to Nihon no Gakkõ [As crianças recém-chegadas e a escola no Japão]. Kokusai Shoin, 2000.

PAK, K. T. Towards Local Citizenship: Japanese Cities Respond to International Migration. Working Paper n.30, The Center for Comparative Immigration Studies (CCIS), University of California at San Diego, 2001.

ROTH, J. H. Brokered Homeland: Japanese Brazilian Migrants in Japan. Cornell University Press, 2002.

SAITO, H. (Org.) A presença japonesa no Brasil. São Paulo: T. A. Queiroz, Edusp, 1980.

SAKURAI, C. Imigração tutelada: os japoneses no Brasil. Campinas, 2000. Tese (Doutorado em Ciências Sociais) - Instituto de Filosofia e Ciências Humanas, Universidade Estadual de Campinas.

SASAKI, E. M. Movimento dekassegui: a experiência migratória e identitária dos brasileiros descendentes de japoneses no Japão. In: REIS, R. R.; SALES, T. (Org.) Cenas do Brasil migrante. São Paulo: Boitempo, 1999. p.243-74.

SASAKI, R. Os problemas que envolvem os trabalhadores brasileiros no Japão. In: CARIGNATO, T. et al. (Org.) Psicanálise, cultura e migração. São Paulo: YM Editora \& Gráfica, 2002. p.239-56.

SCHWARCZ, L. M. O espetáculo das raças - Cientistas, instituições e questão racial no Brasil. São Paulo: Cia. das Letras, 1993.

SHIMIZU, N. Japan, race and equality. The racial equality proporsal of 1919. London, New York: Routledge, 1998.

SHIROMA, E. O. Aspectos da socialização primária como estratégia de socialização organizacional: educação e empresa no Japão. Revista Educação e Sociedade, v.37, p.72-84, dez. 1990. 
SHIROMA, E. O. Sistema educacional e modernização tecnológica: o caso Japão. $R e$ vista Educação e Sociedade, v.45, p.297-308, 1993.

TAKAHASHI, S. O problema educacional das crianças nipo-brasileiras. In: SOCIEDADE DOS CONSULTORES. (Org.) Anais do Simpósio "15 anos do Movimento Dekassegui: Desafios e Perspectivas”. São Paulo, 2001. p.85-91.

TSUDA, T. Transnational Migration and the Nationalization of Ethnic Identity among Japanese Brazilian Return Migrants. Ethos, v.27, n.2, p.145-79, 1999.

Acting Brazilian in Japan: Ethnic Resistance among Return Migrants. Ethnology, v.39, n.1, p.55-71, 2000a.

. Migration and Alienation: Japanese-Brazilian Return Migrants and the Search for Homeland Abroad. The Center for Comparative Immigration Studies (CCIS), Working Paper n.24. University of California, San Diego: 2000b.

Strangers in the Ethnic Homeland: Japanese Brazilian Return Migration in Transnational Perspective. New York: Columbia University Press, 2003.

TSUZUKI, K. Nikkei Burajirujin Ukeire to Chiiki no Henyõ - Aichi-ken Toyota-shi H Danchi wo Jirei to Shite [As transformações da região receptora de nikkeis brasileiros - o caso do conjunto habitacional "H Danchi" da cidade de Toyota, província de Aichi]. In: KOMAI, H. (Ed.) Nihon no Ethnic Shakai [A sociedade étnica do Japão]. Tokyo: Akashi Shõten, 1996. p.310-30.

. Nikkei Burajirujin no Chiiki Seikatsu to Jikakai no Ukeire - Aichi-ken Toyohashi-shi o Jirei to Shite [A vida regional dos nikkeis brasileiros e a recepção da associação civil local - O caso da cidade de Toyohashi, na província de Aichi]. Nagoya Daigaku Shakai Kagaku Ronshu [Revista de Sociologia da Universidade de Nagoya], v.18, p.65-82, 1998.

Gaikokujin Ukeire no Sekinin Shutai ni Kan suru Toshi ma Hikaku - Toyotashi no Jirei wo Chushin ni, õizumi-machi, Hamamatsu-shi to no Hikaku kara" [Comparação entre as cidades que recebem estrangeiros - Comparação entre a cidade de Toyota (como principal), Oizumi e Hamamatsu]. Aichigaku Izumi Daigaku Comyunitie Seisaku Gakubu Kiyõ [Boletim do Departamento de Política Comunitária da Universidade de Izumi, Aichi], n.2, p.127-46, 1999.

VAINER, C. B. Estado e migração no Brasil: da imigração à emigração. In: PATARRA, N. L. (Coord.) Emigração e imigração internacionais no Brasil contemporâneo. São Paulo: FNUAP, 1995. p.39-52.

WATANABE, M. (Org.) Kyõdõ Kenkyu - Dekasegi Nikkei Burajirujin, Jõ - Ronbun Hen: Shurõ to Seikatsu [Dekassegui Nikkei Brasileiro, v.1 - Ensaios: Trabalho e Vida]; Gê - Shiryõ Hen: Taiken to Ishiki [Dekassegui Nikkei Brasileiro, v. 2 - Material Coletado: Experiência e Consciência]. Tokyo: Akashi Shõten, 1995.

YAMANAKA, K. Theory versus Reality in Japanese Immigration Policy. In: CORNELIUS, P. M.; HOLLIFIELD, J. (Ed.) Controlling Immigration: a global Perspective. Stanford, California: Stanford University Press, 1994. p.411-4.

. Return Migration of Japanese-Brazilian to Japan, the nikkeijin as ethnic minority and political construct. Diáspora, v.5, n.1, p.65-98, Spring 1996.

Return Migration of Japanese Brazilian Women: household Strategies and se- 
arch for the "homeland". In: BAXTER, D.; KRULFELD, R. (Ed.) Beyond Boundaries: selected papers on Refugees and Immigrants. American Anthropological Association, 1997. v.5, p.11-34.

YAMAWAKI, C. El "Problema de la Educación" desde el Punto de Vista de los Migrantes: Las Experiências de los Peruanos em Japón. In: YAMADA, M. (Org.) Emigración latinoamericana: comparación interregional entre América del Norte, Europa y Japón - JCAS Symposium Series 19; Population Movement in the Modern World VII. Osaka: Japan Center for Área Studies, National Museum of Ethnology, 2003. p.455-72.

YOSHINO, N. L. Trabalho e saúde de migrantes brasileiros (dekasseguis) no Japão. São Paulo, 1997. Dissertação (Mestrado) - Faculdade de Saúde Pública, Universidade de São Paulo.

YOSHIOKA, R. Crianças brasileiras no Japão. In: SOCIEDADE DOS CONSULTORES. (Org.) Anais do simpósio "15 anos do movimento dekassegui: desafios e perspectivas. São Paulo, 2001. p.71-7.

RESUMO - ESTE TEXTO traça um panorama sobre a migração entre Brasil e Japão. No início do século XX, os japoneses imigraram para o Brasil e, no final desse mesmo século, os brasileiros de origem japonesa estão fazendo o caminho inverso: estão indo ao Japão como trabalhador migrante, sendo conhecidos como dekassegui. Podemos dizer que o deslocamento do brasileiro ao Japão seja um movimento de "volta dos que não foram". Ou seja, é discutível se essa migração de brasileiros ao Japão seja de retorno, pois os contextos e os contingentes são diferentes.

PALAVRAS-CHAVE: Migração internacional, Brasil-Japão, Japoneses no Brasil, Brasileiros no Japão.

ABSTRACT - THIS PAPER presents a panorama about migration process between Brazil and Japan. In the beginning of the $20^{\text {th }}$ Century, the Japanese immigrated to Brazil and, in the end of the same Century, the Japanese descendant Brazilians were taken the inverse way: they were going to Japan as migrant workers, being well known as "Dekassegui". We can call this Brazilian's migration movement to Japan as "Absence of Return". It means, can this populational movement between Brazil and Japan be considered as "Return Migration"? We should consider, first, different contexts and contingents.

KETWORDS: International migration, Brazil-Japan,The Japanese in Brazil, Brazilians in Japan.

Elisa Sasaki é doutoranda em Ciências Sociais no Instituto de Filosofia e Ciências Humanas (IFCH) da Universidade Estadual de Campinas (Unicamp).

@ - emsasaki@pobox.com 